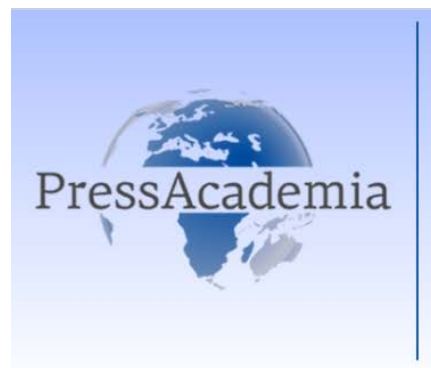

Press Academia Procedia

Global Business Research Congress (GBRC), May 26-27, 2016, Istanbul, Turkey.

\title{
A STUDY ON THE GENERAL STRUCTURE OF THE SERVICE SECTOR IN TURKEY
}

DOI: 10.17261/Pressacademia.2016118657

\author{
Ilhami Mintemur ${ }^{1}$, Mucahit Kurtulus ${ }^{2}$, Omer Mintemur ${ }^{3}$ \\ ${ }^{1}$ Türkiye İstatistik Kurumu, ilhami.mintemur@tuik.gov.tr \\ ${ }^{2}$ Sinop Üniversitesi, mucahitkurtluş@ hotmail.com \\ ${ }^{3}$ Yıldırım Beyazıt Üniversitesi, omermintemur@gmail.com
}

\begin{abstract}
In this study, in Turkish services industry, have been analyzed in terms of number of enterprises, employment, turnover and value added, according to knowledge intensive level of sectors and structure in terms of knowledge-intensive services sector were examined in comparison with European Union countries
\end{abstract}

Keywords: Statistical classifications, knowledge intensive services, services sector

JEL Codes: G20

\section{TÜRKIYE'DE HIZMET SEKTÖRÜNÜN GENEL YAPISI ÜZERINE BIRR ÇALIŞMA}

\section{ÖZET}

Bu çalışmada Türk Hizmet sektöründe bilgi yoğun ve yoğun bilgi içermeyen sektörlerin girişim sayısı, istihdam, ciro ve katma değer açısından bilgi yoğunluk düzeyine göre analiz yapılmış ve Avrupa Birliği ülkeleri ile karşılaştırılarak hizmet sektörünün bilgi yoğun açısından yapısı incelenmiştir.

Anahtar Kelimeler: İstatistikî sınıflamalar, bilgi yoğun hizmetler, hizmet sektörü JEL Kodları: G20

\section{GiRiş}

Bu çalışmada amaç, hizmet sektöründeki girişimlerin sayısı, istihdam, ciro ve katma değer açısından yıllara (2003-2013) göre bilgi yoğunluk açısından değişim olup olmadığını ve Avrupa Birliği ülkeleri ile karşılaştırılarak hizmet sektörünün bilgi yoğun açısından yapısı incelenmiştir. Yüksek teknoloji ve bilgi yoğun hizmet sanayi hakkındaki istatistikler; teknoloji yoğunluklarına göre imalat ve hizmet sanayinde tanımlanan verileri ekonomik, istihdam, bilim, teknoloji ve yenilik açısından incelemektedir. Teknoloji yoğunluğu belirleme de iki temel yaklaşım kullanılmaktadır. Bunlar sektörel ve ürün yaklaşımdır. Üçüncü bir yaklaşım ise Uluslararası Patent Sınıflamasına (IPC) dayanarak biyo-teknoloji patent ve yüksek teknoloji verilerin kullanılmasıdır.[4]

\section{LITERATÜR TARAMASI}

İmalat sanayi; Avrupa Topluluğunda Ekonomik Faaliyetlerin İstatistikî Sınıflamasının (NACE) 2 veya 3 basamaklı faaliyetlerini kullanarak, imalat sanayinde teknoloji yoğunluklarına göre (Araştırma ve Geliştirme Harcamaları / Katma Değer) birbirine yakın grupları oluştururken, hizmetler, NACE Rev.2'nin bölüm ( ikili düzeyde) bazında 
yüksek öğrenim personelinin oranına dayanarak 'Bilgi Yoğun Hizmetler' ve 'Yoğun Bilgi İçermeyen Hizmetler' olmak üzere ikiye ayrılır.

Bilgi yoğun hizmetler ise;

1.Bilgi yoğun yüksek teknoloji hizmetleri (telekomünikasyon, programcılık ve yayıncılık vb. faaliyetleri), 2.Bilgi yoğun piyasa hizmetleri ${ }^{1}$ (finansal aracılar ve yüksek teknoloji hizmetleri hariç) (havayolu, su yolu, hukuk ve muhasebe, reklamcılık vb faaliyetler), 3.Bilgi yoğun finansal hizmetler (finansal hizmet faaliyetleri, Sigorta, reasürans ve emeklilik fonları), 4. Diğer bilgi yoğun hizmetleri (yayımcılık faaliyetler, veterinerlik hizmetleri vb. faaliyetler), 5. Yoğun bilgi içermeyen hizmetleri (toptan ve perakende ticaret, posta ve kurye faaliyetleri, gayrimenkul faaliyetleri, kara taşımacılığı vb. faaliyetler), olmak üzere 5 ana gruba ayrılmıştır [2].

Çalışmanın amacı; hizmet sektörünün, bilgi yoğunluklarını ortaya koymak ve gelişimini izlemektir. Yüksek teknoloji ve bilgi yoğun yüksek teknoloji hizmetler hakkındaki istatistikler, teknoloji yoğunluklarına göre imalat ve hizmet sanayinde tanımlanan verileri ekonomik, istihdam, bilim, teknoloji ve yenilik açısından incelemektedir

\section{VERI VE YÖNTEM}

Bu çalışmada Türkiye İstatistik Kurumunun verileri kullanılmıştır. Veri kapsamı, hizmet istatistiklerinin derlenmesinde tamsayım ve örnekleme yöntemleri bir arada kullanılmaktadır. 20 veya daha fazla çalışanı olan girişimlerde tamsayım yöntemi, 20'den az çalışanı olan girişimlerde örnekleme yöntemi kullanılmaktadır.

Bu çalışmada hizmet sektörü olarak; toptan ve perakende ticaret, ulaştırma ve depolama, konaklama ve yiyecek hizmeti faaliyetleri, bilgi, iletişim, gayrimenkul faaliyetleri, mesleki, bilimsel ve teknik faaliyetler, idari ve destek faaliyetleri, eğitim, insan sağlığı ve sosyal hizmet faaliyetleri, kültür, sanat, eğlence, dinlence ve spor ile diğer hizmet faaliyetleri olarak gruplandırılmıştır.

\section{BULGULAR VE TARTIŞMA}

\subsection{Hizmet Sektöründe Girişim Sayısı Ve İstihdam}

Türkiye'de 2010 yılında, kapsama alınan hizmet sektörlerinde toplam 1.930.000 girişim faaliyette bulunmuştur. Bilgi yoğun yüksek teknoloji hizmet faaliyetlerinde bulunan girişim sayısı 2003 yılında 11.609'dur. Bilgi yoğun yüksek teknoloji hizmeti faaliyetinde bulunan girişimler 2013 yılında 19.183 artarak 30.792'ye ulaşmıştır. Bilgi yoğun yüksek teknoloji hizmeti faaliyetinde bulunan girişim sayısının hizmet sektöründeki girişimlere oranı, 2003-2008 yıllarında ortalama olarak \% 0.97, 2009-2013 yıllarında ise \% 1.33'e yükselmiştir.

Türkiye'de bilgi yoğun yüksek teknoloji hizmet faaliyetinde girişimlerin sayısının, İngiltere'de Bilgi yoğun yüksek teknoloji hizmeti faaliyetinde bulunan girişim sayısına oranı \% 19.3'dür. Bu oran Fransa'ya göre \% 27.4 ve Almanya göre \% 32.1'i kadar iken; ülkemiz Finlandiya, Avusturya, Portekiz, Danimarka ve Slovenya gibi ülkelerden daha çok yüksek teknolojik faaliyetinde bulunan girişimlere sahiptir (Çizelge 5).

Çizelge 1: Bilgi yoğun hizmet faaliyetlere göre girişim oranları (\%)

\begin{tabular}{|lrrrrrrrrrr|r|}
\hline Hizmet düzeyi & $\mathbf{2 0 0 3}$ & $\mathbf{2 0 0 4}$ & $\mathbf{2 0 0 5}$ & $\mathbf{2 0 0 6}$ & $\mathbf{2 0 0 7}$ & $\mathbf{2 0 0 8}$ & $\mathbf{2 0 0 9}$ & $\mathbf{2 0 1 0}$ & $\mathbf{2 0 1 1}$ & $\mathbf{2 0 1 2}$ & $\mathbf{2 0 1 3}$ \\
\hline $\begin{array}{l}\text { Bilgi yoğun yüksek } \\
\text { teknoloji hizmetleri }\end{array}$ & 0.8 & 0.8 & 0.8 & 1.0 & 1.2 & 1.2 & 1.2 & 1.4 & 1.3 & 1.3 & 1.4 \\
\hline $\begin{array}{l}\text { Bilgi yoğun piyasa } \\
\text { hizmetleri }\end{array}$ & 5.0 & 5.1 & 4.7 & 5.3 & 5.6 & 5.7 & 6.4 & 6.5 & 6.6 & 6.8 & 7.1 \\
\hline $\begin{array}{l}\text { Bilgi yoğun finansal } \\
\text { hizmetler }\end{array}$ & 0.4 & 0.3 & 0.3 & 0.3 & 0.3 & 0.4 & 0.9 & 0.9 & 0.8 & 0.8 & $0, .8$ \\
\hline $\begin{array}{l}\text { Diğgr bilgi yoğun } \\
\text { hizmetler }\end{array}$ & 3.2 & 3.3 & 2.8 & 3.0 & 3.0 & 3.0 & 2.9 & 2.7 & 2.8 & 2.9 & 3.3 \\
\hline $\begin{array}{l}\text { Yoğun bilgi içermeyen } \\
\text { hizmetler }\end{array}$ & 90.7 & 90.5 & 91.4 & 90.5 & 89.9 & 89.8 & 88.6 & 88.5 & 88.4 & 88.1 & 87.4 \\
\hline
\end{tabular}

\footnotetext{
${ }^{1}$ Bilgi yoğun piyasa hizmetleri diye kullanılacaktır
} 
Hizmet sektöründe girişim sayısı, yoğun bilgi içermeyen hizmet faaliyetlerde yoğunlaşmaktadır. Hizmet sektöründe 2003-2013 yıllarında ortalama girişimlerin \% 89.4'ü yoğun bilgi içermeyen faaliyetler de bulunmaktadır. Bilgi yoğun yüksek teknoloji hizmet faaliyetinde bulunan girişimlerin oranı 2003-2013 yıllarında ortalama olarak \% 1.1 'ine sahiptir.

Çizelge 2: Bilgi yoğun hizmetlere göre istihdam (000 kişi)

\begin{tabular}{|c|c|c|c|c|c|c|c|c|c|c|c|}
\hline Hizmet düzeyleri & 2003 & 2004 & 2005 & 2006 & 2007 & 2008 & 2009 & 2010 & 2011 & 2012 & 2013 \\
\hline $\begin{array}{l}\text { Bilgi yoğun yüksek } \\
\text { teknoloji hizmetleri }\end{array}$ & 127 & 130 & 134 & 134 & 140 & 155 & 147 & 155 & 164 & 172 & 185 \\
\hline $\begin{array}{l}\text { Bilgi yoğun piyasa } \\
\text { hizmetleri }\end{array}$ & 294 & 345 & 409 & 475 & 515 & 537 & 544 & 609 & 694 & 765 & 841 \\
\hline $\begin{array}{l}\text { Bilgi yoğun finansal } \\
\text { hizmetler }\end{array}$ & 195 & 197 & 205 & 213 & 233 & 258 & 286 & 295 & 299 & 309 & 314 \\
\hline $\begin{array}{l}\text { Diğer bilgi yoğun } \\
\text { hizmetleri }\end{array}$ & 230 & 271 & 302 & 343 & 377 & 419 & 412 & 472 & 520 & 597 & 656 \\
\hline $\begin{array}{l}\text { Yoğun bilgi içermeyen } \\
\text { hizmetler }\end{array}$ & 3.399 & 3.886 & 4.794 & 4.946 & 5.096 & 5.200 & 4.941 & 5.005 & 5.635 & 6.042 & 6.174 \\
\hline Toplam & 4.245 & 4.829 & 5.844 & 6.111 & 6.361 & 6.569 & 6.330 & 6.536 & 7.312 & 7.885 & 8.171 \\
\hline
\end{tabular}

2013 yılında hizmetler sektöründe $\mathbf{8 . 1 7 1 . 0 0 0 ~ k i s ̧ i ~ i s t i h d a m ~ e d i l m i s ̧ t i r . ~ B i l g i ~ y o g ̆ u n ~ y u ̈ k s e k ~ t e k n o l o j i ~ h i z m e t ~}$ faaliyetlerinde istihdam edilen $\mathbf{1 8 5 . 0 0 0}$ kişi, hizmet sektör istihdamının \% 2.3'üne denk gelmektedir. 2013 yılında, 2003 yılına göre en fazla istihdam artışı yoğun bilgi içermeyen hizmetleri düzeyinde meydana gelmiştir. 2003 yılında 3.399 .000 kişi çalışırken 2013 yılında \% 81.7 artışla 6.174 .000 kişiye ulaşılmıştır.

Çizelge 3: Bilgi yoğun hizmet faaliyetlerine göre istihdam oranları (\%)

\begin{tabular}{|lccccccccccc|}
\hline Hizmet düzeyleri & 2003 & 2004 & 2005 & 2006 & 2007 & 2008 & 2009 & 2010 & 2011 & 2012 & 2013 \\
\hline $\begin{array}{l}\text { Bilgi yoğun yüksek } \\
\text { teknoloji hizmetleri }\end{array}$ & 3.0 & 2.7 & 2.3 & 2.2 & 2.2 & 2.4 & 2.3 & 2.4 & 2.2 & 2.2 & 2.3 \\
\hline $\begin{array}{l}\text { Bilgi yoğun piyasa } \\
\text { hizmetleri }\end{array}$ & 6.9 & 7.1 & 7.0 & 7.8 & 8.1 & 8.2 & 8.6 & 9.3 & 9.5 & 9.7 & 10.3 \\
\hline $\begin{array}{l}\text { Bilgi yoğun finansal } \\
\text { hizmetler }\end{array}$ & 4.6 & 4.1 & 3.5 & 3.5 & 3.7 & 3.9 & 4.5 & 4.5 & 4.1 & 3.9 & 3.8 \\
\hline $\begin{array}{l}\text { Diğgr bilgi yoğun } \\
\text { hizmetler }\end{array}$ & 5.4 & 5.6 & 5.2 & 5.6 & 5.9 & 6.4 & 6.5 & 7.2 & 7.1 & 7.6 & 8.0 \\
\hline $\begin{array}{l}\text { Yoğun bilgi içermeyen } \\
\text { hizmetler }\end{array}$ & 80.1 & 80.5 & 82.0 & 80.9 & 80.1 & 79.1 & 78.1 & 76.6 & 77.1 & 76.6 & 75.6 \\
\hline
\end{tabular}

Hizmet sektöründe istihdam, yoğun bilgi içermeyen hizmet faaliyetlerinde yoğunlaşmaktadır. Hizmet sektöründe 2003-2013 yıllarında ortalama istihdamın \% 78.8'i yoğun bilgi içermeyen hizmet faaliyetlerinde bulunmaktadır. Bilgi yoğun yüksek teknoloji hizmetlerinde yaratılan istihdam 2003-2013 yıllarında ortalama istihdamın \% 2.4 'üne sahiptir. 
Çizelge 4: Seçilmiş AB ülkelerinde bilgi yoğun yüksek teknoloji hizmetlerinde çalışanlar sayısı, 2011

\begin{tabular}{lrr}
\hline Ülke & ístihdam (000 kişi) & $\begin{array}{r}\text { Türkiye'nin ülkelere göre } \\
\text { istihdam oranı (\%) }\end{array}$ \\
\hline Almanya & 1.159 & 14.2 \\
\hline Fransa & 799 & 20.5 \\
İtalya & 540 & 30.4 \\
\hline İspanya & 494 & 33.2 \\
Polonya & 316 & 51.9 \\
\hline Hollanda & 263 & 62.4 \\
Türkiye & 164 & 100.0 \\
Romanya & 138 & 118.8 \\
Çek Cumhuriyeti & 123 & 133.3 \\
\hline Avusturya & 101 & 162.4 \\
Macaristan & 100 & 164.0 \\
\hline Danimarka & 99 & 165.7 \\
\hline Portekiz & 82 & 200.0 \\
\hline Finlandiya & 33 & 497.0 \\
\hline Slovenya & 28 & 585.7 \\
\hline
\end{tabular}

2011 yılında Türkiye'de, bilgi yoğun yüksek yeknoloji hizmet faaliyetlerinde çalışanların sayısı Almanya'daki aynı teknoloji düzeyinde çalışanların \% 14.2'si, Fransa'nın \% 20.5'i, İtalya'nın \% 30.4'ü oranında iken, Romanya, Macaristan, Danimarka ve Portekiz gibi ülkelerden daha fazla istihdam yaratılmaktadır.

Çizelge 5: Seçilmiş AB ülkelerinde bilgi yoğun yüksek teknoloji hizmetlerinde girişim sayısı, ciro ve katma değerler, 2010

\begin{tabular}{|c|c|c|c|c|c|c|}
\hline Ülkeler & $\begin{array}{r}\text { Girişim } \\
\text { sayısı }\end{array}$ & $\begin{array}{r}\text { Türkiye'nin } \\
\text { ülkelere göre } \\
\text { girişim oranı } \\
(\%)\end{array}$ & $\begin{array}{r}\text { Ciro } \\
\text { Değeri } \\
\text { Milyon Euro }\end{array}$ & $\begin{array}{l}\text { Türkiye'nin } \\
\text { ülkelere göre } \\
\text { ciro oranı (\%) }\end{array}$ & $\begin{array}{r}\text { Katma } \\
\text { Değer } \\
\text { Milyon } \\
\text { Euro }\end{array}$ & $\begin{array}{r}\text { Türkiye'nin } \\
\text { ülkelere } \\
\text { göre katma } \\
\text { değer oranı } \\
\text { (\%) }\end{array}$ \\
\hline İngiltere & 139.017 & 19.3 & 209.558 & 9.5 & 90.704 & 8.6 \\
\hline İtalya & 101.381 & 26.5 & 104.493 & 19.1 & 48.859 & 16.0 \\
\hline Fransa & 98.183 & 27.4 & 157.163 & 12.7 & 68.564 & 11.4 \\
\hline Almanya & 83.584 & 32.1 & 185.905 & 10.7 & 85.133 & 9.2 \\
\hline Hollanda & 52.436 & 51.2 & 50.155 & 39.7 & 24.112 & 32.4 \\
\hline Polonya & 50.430 & 53.3 & 22.094 & 90.1 & 10.382 & 75.2 \\
\hline İspanya & 42.294 & 63.5 & 73.235 & 27.2 & 33.875 & 23.0 \\
\hline Macaristan & 33.846 & 79.4 & 9.296 & 214.2 & 3.769 & 207.1 \\
\hline $\begin{array}{l}\text { Çek } \\
\text { Cumhuriyeti }\end{array}$ & 30.625 & 87.7 & 12.390 & 160.7 & 5.660 & 137.9 \\
\hline Türkiye ${ }^{2}$ & 26.867 & 100.0 & 19.910 & 100.0 & 7.807 & 100.0 \\
\hline Romanya & 19.201 & 139.9 & 7.786 & 255.7 & 3.506 & 222.6 \\
\hline Avusturya & 18.612 & 144.4 & 11.702 & 170.1 & 7.238 & 107.8 \\
\hline Portekiz & 14.619 & 183.8 & 12.404 & 160.5 & 5.285 & 147.7 \\
\hline Danimarka & 12.681 & 211.9 & 20.205 & 98.5 & 8.916 & 87.6 \\
\hline Slovenya & 8.313 & 323.2 & 2.850 & 698.6 & 3.508 & 222.5 \\
\hline Finlandiya & 8.209 & 327.3 & 13.172 & 151.2 & 6.057 & 128.9 \\
\hline
\end{tabular}

\footnotetext{
${ }^{2}$ Ciro ve katma değer, 2010 yııının ortalama Euro satış fiyatına bölünerek hesaplanmıştır
} 
Türkiye bilgi yoğun yüksek teknoloji hizmet faaliyetlerinde, 2010 yılında 19.910 milyon Euro'luk ciro ve 7.807 milyon Euro'luk katma değer elde etmiştir. 2010 yılında yaratılan ciro değeri; aynı yıl Almanya'da bilgi yoğun yüksek teknoloji hizmet faaliyetlerinde; üretilen cironun \% 9.5'i ve katma değer de ise Almanya'dakinin \%8.6'sına denk gelmektedir. 2010 yılında Türkiye'de bilgi yoğun yüksek teknoloji hizmet faaliyetlerinde; yaratılan ciro ve katma değer, Avusturya, Romanya, Portekiz, Slovenya gibi ülkelerden daha fazla olmasına rağmen, Almanya, Fransa, İngiltere, Hollanda, İtalya gibi gelişmiş ülkelerden sonra gelmektedir.

Çizelge 6: Bilgi yoğun hizmet faaliyetlerine göre ciro oranları (\%)

\begin{tabular}{|lccccccccccc|}
\hline Hizmet düzeyleri & 2003 & 2004 & 2005 & 2006 & 2007 & 2008 & 2009 & 2010 & 2011 & 2012 & 2013 \\
\hline $\begin{array}{l}\text { Bilgi yoğun yüksek } \\
\text { teknoloji hizmetleri }\end{array}$ & 3.8 & 3.5 & 2.9 & 3.4 & 2.8 & 2.8 & 3.2 & 3.3 & 3.0 & 2.8 & 2.9 \\
\hline $\begin{array}{l}\text { Bilgi yoğun piyasa } \\
\text { hizmetleri }\end{array}$ & 3.6 & 4.1 & 3.5 & 3.9 & 4.1 & 4.8 & 4.8 & 4.8 & 4.9 & 4.5 & 5.0 \\
\hline $\begin{array}{l}\text { Bilgi yoğun finansal } \\
\text { hizmetler }\end{array}$ & 5.3 & 4.2 & 4.3 & 4.7 & 4.4 & 4.5 & 7.2 & 6.1 & 5.9 & 5.9 & 6.1 \\
\hline $\begin{array}{l}\text { Diğer bilgi yoğun } \\
\text { hizmetler }\end{array}$ & 1.4 & 1.3 & 1.5 & 1.7 & 1.7 & 1.9 & 2.1 & 2.2 & 2.3 & 2.3 & 2.6 \\
\hline $\begin{array}{l}\text { Yoğun bilgi } \\
\text { içermeyen } \\
\text { hizmetler }\end{array}$ & 85.9 & 86,9 & 87.7 & 86.4 & 87.1 & 86.0 & 82.7 & 83.5 & 83.9 & 84.5 & 83.4 \\
\hline
\end{tabular}

2003-2013 yıllarında yoğun bilgi içermeyen hizmetlerde yaratılan ciro değeri stabil bir durum göstermektedir. Hizmetler sektörü; yaratılan ciro, yoğun bilgi içermeyen hizmet faaliyetlerinde yoğunlaşmaktadır. 2003-2013 yıllarında ortalama ciro değerinin \% 85.3'ü yoğun bilgi içermeyen hizmetler faaliyetinde meydana gelmiştir.

Bilgi yoğun teknoloji hizmet faaliyetlerinde; yaratılan ciro değeri 2003-2013 yıllarında ortalama ciro değerinin \% 3.1'ine sahiptir. 


\section{Şekil 1: Bilgi yoğun hizmetlere göre katma değer oranları (\%)}

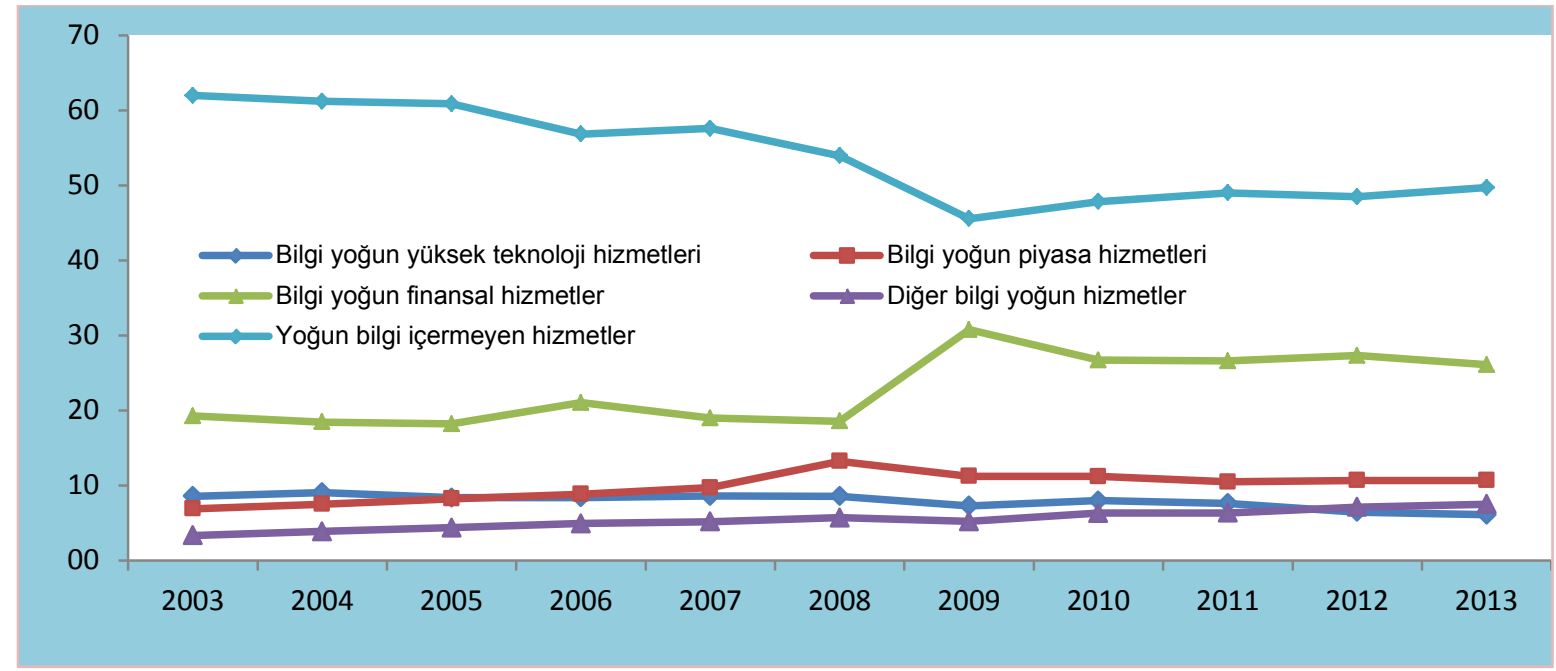

2003-2013 yıllarında yoğun bilgi içermeyen hizmet faaliyetlerinde yaratılan katma değerde 2009 yılında bir kırılma olmuştur. Bu kırılma bilgi yoğun finansal hizmetlere kaymış durumdadır. Hizmetler sektöründe yaratılan katma değer, yoğun bilgi içermeyen hizmet faaliyetlerinde yoğunlaşmaktadır. 2003-2013 yıllarında ortalama katma değerin \% 53.9'u yoğun bilgi içermeyen hizmet faaliyetlerinde meydana gelmiştir.

Bilgi yoğun teknoloji hizmetlerinde yaratılan katma değer; 2003-2013 yıllarında ortalama olarak katma değerin \% 7.9'una sahiptir.

Bilgi yoğun finansal hizmetlerin 2008 yılından sonra katma değerinin yükselmesinin nedeni, kapsama yeni girişimlerin alınmasıdır.(2009 yııında, Tüketici Finansman Şirketleri, Ikrazatçılar, Varlık Yönetim Şirketleri, Menkul Kıymet, Gayrimenkul ve Girişim Sermayesi Yatııım Ortaklıkları, Sigorta Acenteleri (gerçek kişi) ve Sigorta Eksperleri, Borsalar (iMKB, VOB ve IAB), Vadeli Işlemler Aracılık Şirketleri, Portföy Yönetim Şirketleri, Kredi Garanti Fonu A.Ş ve Merkezi Kayıt Kuruluşu A.Ş. kapsama dahil edilmiştir)

Şekil 2 : Bilgi yoğun hizmet faaliyetlerinde ücretsiz aile fertlerin toplam çalışanlar içindeki oranları (\%)

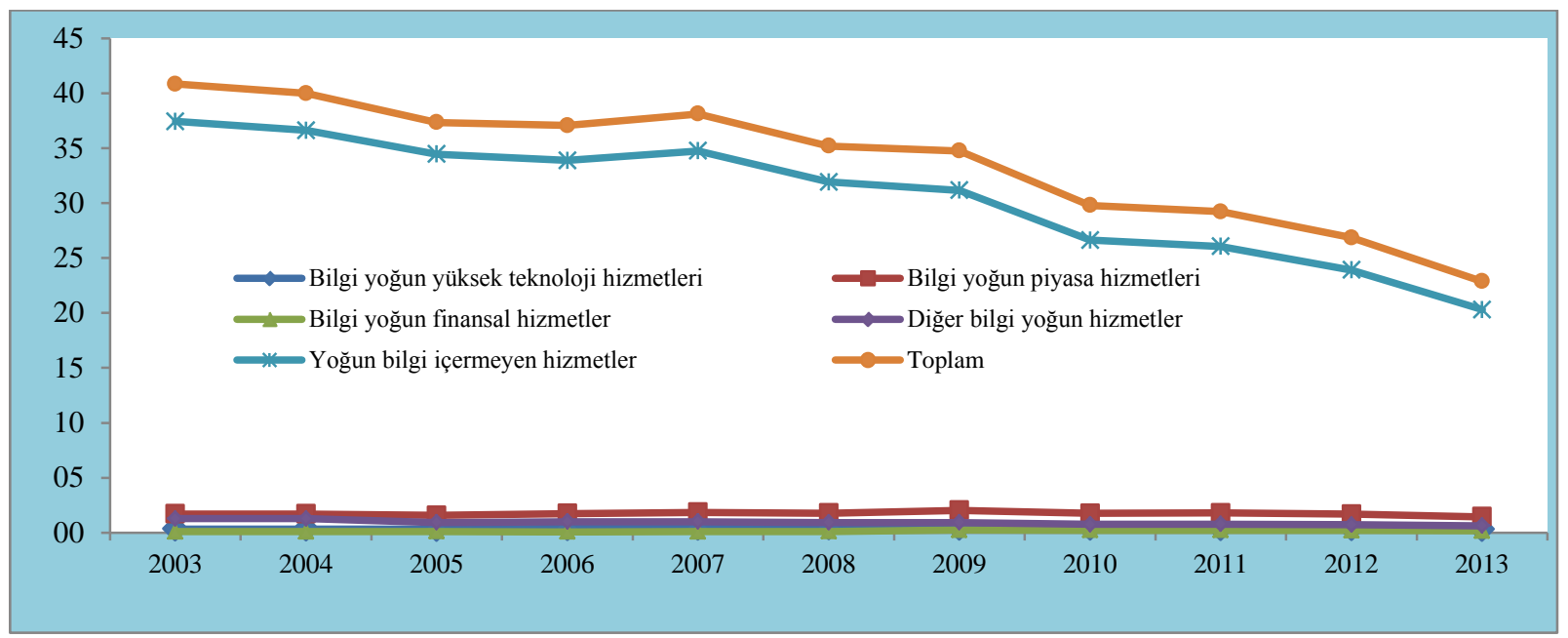

2003 yılında bilgi yoğun hizmet sektöründe toplam çalışanların \% 40.8'i ücretsiz aile fertleri iken, 2013 yılında bu oran \% 22.9'a düşmüştür.

Aynı şekilde 2003 yılında yoğun bilgi içermeyen hizmet sektöründe çalışanların \% 37.4'ü ücretsiz aile fertlerinden oluşurken, 2013 yılında bu oran \% 20.3'e düşmüştür. 
Diğer bilgi yoğun hizmet sektör düzeylerinde 2003-2013 yıllarında ücretsiz çalışan aile fertleri oranlarında önemli bir değişim meydana gelmemiştir.

Şekil 3 : Yüksek teknoloji üretimi ve bilgi yoğun yüksek teknoloji hizmet faaliyetlerinde istihdam oranları (\%)

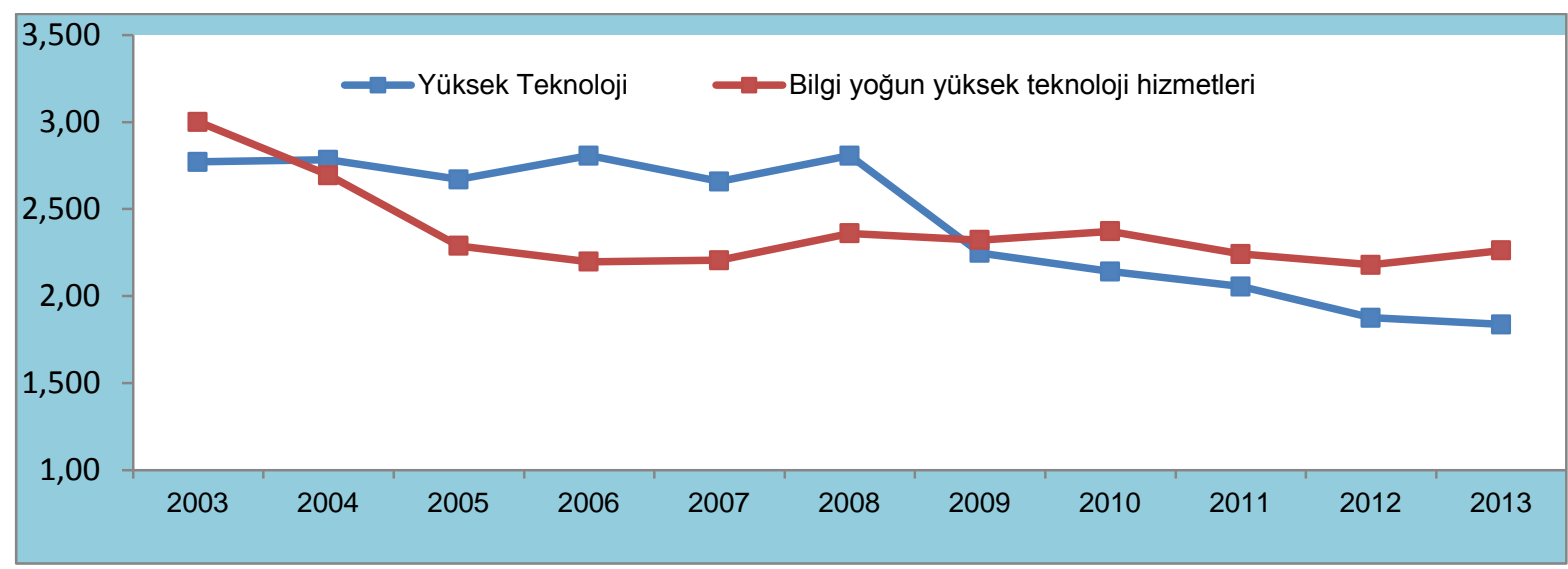

İmalat sanayinde yüksek teknoloji üretimi ve hizmet sektöründe, bilgi yoğun yüksek teknoloji hizmetlerinde çalışanların oranı \% 3'ün altında seyretmektedir. Bu iki sektörde ve iki düzeyde çalışanların oranı 2003-2013 yıllarında ortalama çalışanların \% 2.4'üdür.

Şekil 4 : Düşük teknoloji ve yoğun bilgi içermeyen hizmet faaliyetlerinde istihdam oranları (\%)

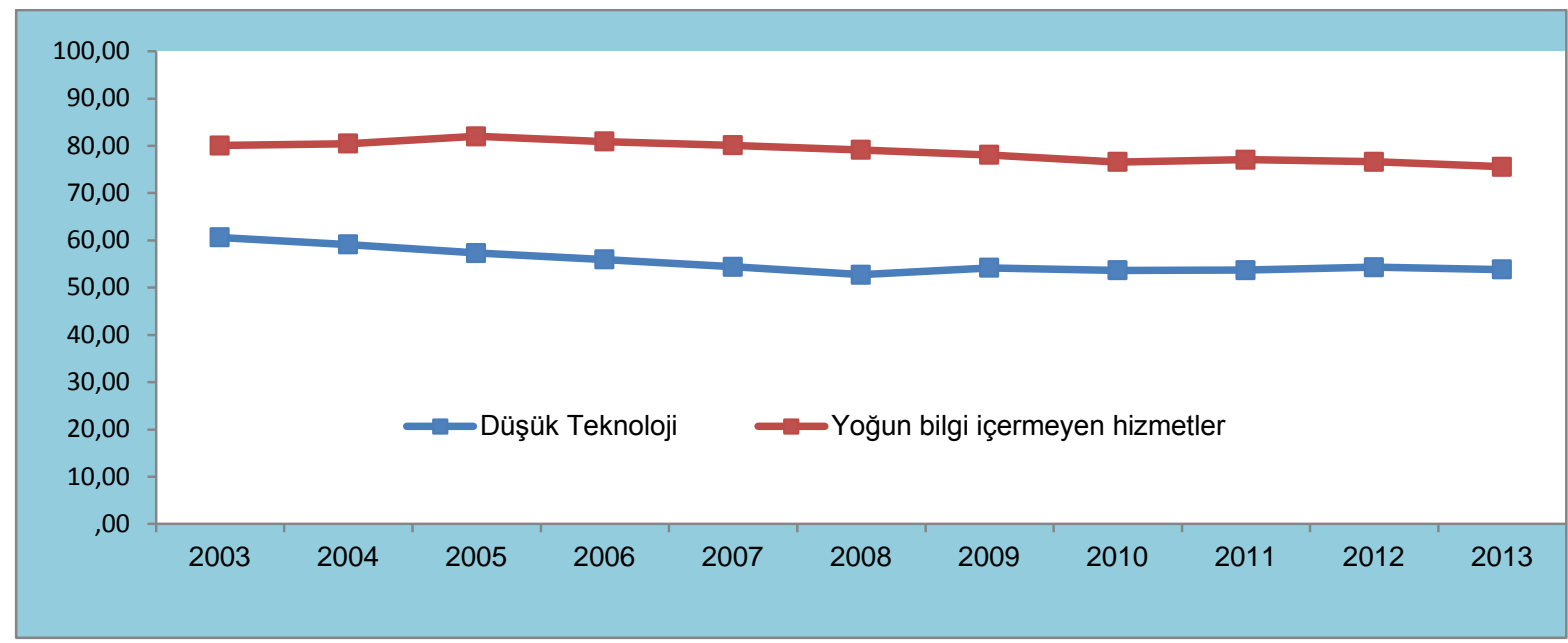

İmalat sanayi ve hizmet sektörlerinde çalışanların yarıdan fazlası, düşük teknoloji ve bilgi içermeyen sektörlerde çalışmaktadır. İmalat sanayinde 2003-2013 yıllarında ortalama çalışanların \% 55.4'ü düşük teknoloji düzeyinde, hizmet sektöründe çalışanların \% 78.8'i yoğun bilgi içermeyen hizmetlerde istihdam edilmektedir. 
Çizelge 7 : 2003-2013 yıllarında istihdamın oransal ortalaması, standart sapması ve değişim katsayısı

\begin{tabular}{lrrr}
\hline Hizmet düzeyleri & $\begin{array}{r}\text { Geometrik } \\
\text { Ortalama }\end{array}$ & $\begin{array}{r}\text { Standart } \\
\text { sapma }\end{array}$ & $\begin{array}{r}\text { Değişim } \\
\text { Katsayısı (\%) }\end{array}$ \\
\hline Bilgi yoğun yüksek teknoloji hizmetleri & 2.4 & 0.3 & 10.6 \\
Bilgi yoğun piyasa hizmetleri & 8.3 & 1.2 & 14.0 \\
Bilgi yoğun finansal hizmetler & 4.0 & 0.4 & 9.8 \\
Diğer bilgi yoğun hizmetler & 6.3 & 1.0 & 15.1 \\
Yoğun bilgi içermeyen hizmetler & 78.8 & 2.1 & 2.7 \\
\hline
\end{tabular}

Ortalamadan en fazla sapma yoğun bilgi içermeyen hizmetlerde görünmektedir. Değişim katsayısına göre en az değişim \% 2.7 ile yoğun bilgi içermeyen hizmetlerde ortaya çıkmaktadır.

\section{SONUÇ}

\subsection{Bulgular Ve Öneriler}

Türkiye hizmet sektörü; 2003-2013 yıllarında incelenen göstergeler açısından (girişim sayısı, istihdam, ciro ve katma değer) yoğun bilgi içermeyen hizmet (toptan ve perakende ticaret, posta ve kurye faaliyetleri, gayrimenkul faaliyetleri, kara taşımacılığı vb. faaliyetler) faaliyetlerinde yoğunlaşmaktadır.

2003-2013 yıllarında;

o Girişim sayısının \% 89.4'ü,

o İstihdamın \% 78.8'i,

o Katma değerin \% 53.9'u,

o Ciro değerinin\% 85.3'ü yoğun bilgi içermeyen hizmet faaliyetlerinde bulunmaktadır

- Bilgi yoğun teknoloji hizmet faaliyetlerinde yaratılan istihdam, ciro ve katma değer gelişmiş $A B$ ülkelerinin hayli gerisindedir.

- 2003-2013 yılları arasında hizmetler sektöründe bilgi yoğun yüksek teknoloji hizmetler düzeyinde önemli bir değişim olmamıştır.

- Ücretsiz çalışanlar yoğun olarak 'yoğun bilgi içermeyen hizmet'sektöründe yoğunlaşmaktadırlar.

- "Yoğun bilgi içermeyen hizmet faaliyetlerinde ücretsiz çalışanlar yıllara göre sürekli bir düşüş eğilimi göstermektedirler.

- İmalat sanayi ve hizmet sektörlerinde çalışanların yarıdan fazlası, düşük teknoloji ve bilgi içermeyen sektörlerde çalışmaktadır. İmalat sanayinde 2003-2013 yıllarında ortalama düşük teknoloji faaliyetlerinde çalışanların \% 55.4'ü ve hizmet sektöründe çalışanların \% 78.8'i yoğun bilgi içermeyen hizmetlerde istihdam edilmektedir.

- Teknoloji sınıflaması ve bilgi yoğun sınıflamasının ulusal düzeyde geliştirilmesi,

- Teknoloji düzeylerine ve bilgi yoğun hizmet düzeylerine göre dönemsel ve yıllık baz istatistiklerin yayınlanmasında fayda vardır. 


\section{KAYNAKLAR}

Eurostat, High-techstatistics, 2013

Yıllık Sanayi ve Hizmet İstatistikleri (NACE Rev.1.1), Ekonomik Faaliyetlere Göre Bazı Temel Göstergeler http://www.tuik.gov.tr/PreTablo.do?alt_id=1035,

Yıllık Sanayi ve Hizmet İstatistikleri (NACE Rev.1.1), Ekonomik Faaliyetlere Göre Bazı Temel Göstergeler, http://www.tuik.gov.tr/PreTablo.do?alt_id=1076

Thomas JAEGERS, Carmen LIPP-LINGUA, Digna AMIL, High-technology and medium-high technology industries main drivers of EU-27's industrial growth, Eurostat, ISSN:1977-0316 Cataloguenumber:KS-SF-13-001-EN-N

Türkiye İstatistik Kurumu, Avrupa Topluluğunda Ekonomik Faaliyetlerin İstatistik Sınıflaması, Ankara 2010, Türkiye İstatistik Kurumu Matbaası,

Türkiye İstatistik Kurumu, Türkiye İstatistik Yıllığı, Ankara 2011, Türkiye İstatistik Kurumu Matbaası, Nisan, 2013

Türkiye İstatistik Kurumu, Türkiye İstatistik Yıllığı, Ankara 2012, Türkiye İstatistik Kurumu Matbaası, Haziran 2013

file://C:/Users/16420137486/AppData/Local/Microsoft/Windows/Temporary\%20Internet\%20Files/Content.IE5/L7381CEC/ISTKON9_OZET KITAPCIGI.pdf

Mücahit KURTULUŞ, ilhami MiNTEMUR, Ahmet PALAS, Türk İmalat Sanayinin Teknoloji Üretim Düzeyleri http://www.istkon.net/files/istkon9/ISTKON9_OZET_KITAPCIGI.pdf, 


\section{EKLER :}

\section{EK 1:Bilgi Yoğun Hizmet Faaliyetleri}

\begin{tabular}{|c|c|c|}
\hline Kod & Tanım & Hizmet tipi \\
\hline 64 & $\begin{array}{l}\text { Finansal hizmet faaliyetleri (Sigorta ve emeklilik } \\
\text { fonları hariç) }\end{array}$ & \multirow{3}{*}{ Bilgi yoğun finansal hizmetler } \\
\hline 65 & $\begin{array}{l}\text { Sigorta, reasürans ve emeklilik fonları (Zorunlu sosyal } \\
\text { güvenlik hariç) }\end{array}$ & \\
\hline 66 & $\begin{array}{l}\text { Finansal hizmetler ile sigorta faaliyetleri için yardımcı } \\
\text { faaliyetler }\end{array}$ & \\
\hline 50 & Su yolu taşımacılığı & \multirow{9}{*}{$\begin{array}{l}\text { Bilgi yoğun piyasa hizmetleri (finansal } \\
\text { aracılar ve yüksek teknoloji hizmetleri } \\
\text { hariç): }\end{array}$} \\
\hline 51 & Hava yolu taşımacılığı & \\
\hline 69 & Hukuk ve muhasebe faaliyetleri & \\
\hline 70 & $\begin{array}{l}\text { İdare merkezi faaliyetleri; idari danışmanlık } \\
\text { faaliyetleri }\end{array}$ & \\
\hline 71 & $\begin{array}{l}\text { Mimarlık ve mühendislik faaliyetleri; teknik test ve } \\
\text { analiz faaliyetler }\end{array}$ & \\
\hline 73 & Reklamcılık ve piyasa araştırması & \\
\hline 74 & Diğer mesleki, bilimsel ve teknik faaliyetler & \\
\hline 78 & İstihdam faaliyetler & \\
\hline 80 & Güvenlik ve soruşturma faaliyetleri & \\
\hline 59 & $\begin{array}{l}\text { Sinema filmi, video ve televizyon programları } \\
\text { yapımcılığı, ses kaydı ve müzik yayınlama faaliyetleri }\end{array}$ & \multirow{6}{*}{ Bilgi Yoğun Yüksek Teknoloji Hizmetleri } \\
\hline 60 & Programcılık ve yayıncılık faaliyetleri & \\
\hline 61 & Telekomünikasyon & \\
\hline 62 & $\begin{array}{l}\text { Bilgisayar programlama, danışmanlık ve ilgili } \\
\text { faaliyetler }\end{array}$ & \\
\hline 63 & Bilgi hizmet faaliyetleri & \\
\hline 72 & Bilimsel araştırma ve geliştirme faaliyetleri & \\
\hline 58 & Yayımcılık faaliyetleri & \multirow{8}{*}{ Diğer bilgi yoğun hizmetleri } \\
\hline 75 & Veterinerlik hizmetleri & \\
\hline 84 & Kamu yönetimi ve savunma; zorunlu sosyal güvenlik ${ }^{3}$ & \\
\hline 85 & Eğitim & \\
\hline 86 & İnsan sağlığı hizmetleri & \\
\hline 87 & Yatılı bakım faaliyetleri & \\
\hline 88 & Barınacak yer sağlanmaksızın verilen sosyal hizmetler & \\
\hline 90 & $\begin{array}{l}\text { Yaratıcı sanatlar, gösteri sanatları ve eğlence } \\
\text { faaliyetleri }\end{array}$ & \\
\hline
\end{tabular}

${ }^{3} 84,94,97,98$ ve 99 Bölümlere ilişkin veriler analize dahil edilmemiştir. 


\begin{tabular}{|c|c|c|}
\hline 91 & $\begin{array}{l}\text { Kütüphaneler, arşivler, müzeler ve diğer kültürel } \\
\text { faaliyetler }\end{array}$ & \multirow{22}{*}{$\begin{array}{l}\text { Yoğun bilgi içermeyen } \\
\text { Hizmetler }\end{array}$} \\
\hline 92 & Kumar ve müşterek bahis faaliyetleri & \\
\hline 93 & Spor faaliyetleri, eğlence ve dinlence faaliyetleri & \\
\hline 53 & Posta ve kurye faaliyetleri & \\
\hline 94 & Üye olunan kuruluşların faaliyetleri & \\
\hline 96 & Diğer hizmet faaliyetleri & \\
\hline 97 & $\begin{array}{l}\text { Ev içi çalışan personelin işverenleri olarak hane } \\
\text { halklarının faaliyetleri }\end{array}$ & \\
\hline 98 & $\begin{array}{l}\text { Hane halkları tarafından kendi kullanımlarına yönelik } \\
\text { olarak üretilen ayrım yapılmamış mal ve hizmetler }\end{array}$ & \\
\hline 99 & Uluslararası örgütler ve temsilciliklerinin faaliyetleri & \\
\hline 45 & $\begin{array}{l}\text { Motorlu kara taşıtlarının ve motosikletlerin toptan ve } \\
\text { perakende ticareti ile onarımı }\end{array}$ & \\
\hline 46 & $\begin{array}{l}\text { Toptan ticaret (Motorlu kara taşıtları ve motosikletler } \\
\text { hariç) }\end{array}$ & \\
\hline 47 & $\begin{array}{l}\text { Perakende ticaret (Motorlu kara taşıtları ve } \\
\text { motosikletler hariç) }\end{array}$ & \\
\hline 49 & Kara taşımacılığı ve boru hattı taşımacılığı & \\
\hline 52 & Taşımacılık için depolama ve destekleyici faaliyetler & \\
\hline 55 & Konaklama & \\
\hline 56 & Yiyecek ve içecek hizmeti faaliyetleri & \\
\hline 68 & Gayrimenkul faaliyetleri & \\
\hline 77 & Kiralama ve leasing faaliyetleri & \\
\hline 79 & $\begin{array}{l}\text { Seyahat acentesi, tur operatörü ve diğer rezervasyon } \\
\text { hizmetleri ve ilgili faaliyetler }\end{array}$ & \\
\hline 81 & $\begin{array}{l}\text { Binalar ile ilgili hizmetler ve çevre düzenlemesi } \\
\text { faaliyetleri }\end{array}$ & \\
\hline 82 & Büro yönetimi, büro destek ve iş destek faaliyetleri & \\
\hline 95 & $\begin{array}{l}\text { Bilgisayarların, kişisel eşyaların ve ev eşyalarının } \\
\text { onarımı }\end{array}$ & \\
\hline
\end{tabular}

